\title{
Skillful management of exodontia complication to prevent dreadful sequelae
}

\author{
P Bansal ${ }^{1}$, S Rohatgi ${ }^{2}$, N Sheokand ${ }^{3}$ \\ ${ }^{1}$ MDS,Associate professor. Department of Oral and Maxillofacial Surgery. Sudha rustagi college of dental sciences, kheri more, \\ Faridabad, Haryana, India. \\ ${ }^{2}$ MDS,Assistant professor, Department of Periodontics. Sudha rustagi college of dental sciences, Faridabad. \\ ${ }^{3}$ BDS,Captain (Army dental corps) Indian army.
}

Correspondence:

Department of Oral and Maxillofacial Surgery.

Sudha rustagi college of dental sciences,

kheri more, Faridabad, Haryana, India.

E-mail: pankajbansal363@gmail.com

Bansal P, Rohatgi S, Sheokand N. Skillful management of exodontia complication to prevent dreadful sequelae. J Clin Exp Dent. 2011;3(4):e340-2. http://www.medicinaoral.com/odo/volumenes/v3i4/jcedv3i4p340.pdf

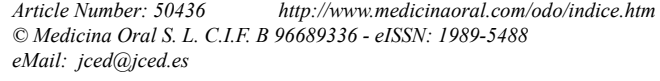

\begin{abstract}
Successful surgical treatments depend upon accurate diagnosis, judicious treatment planning, selection and execution of an appropriate surgical technique, and on a well monitored post-operative period. However, despite these precautions, extraction of teeth (particularly third molar) is exposed to the accidents and complications common to all buccomaxillary and facial interventions. A maxillary third molar may be displaced in maxillary sinus, nearby soft tissue, or may migrate in a superioposterior direction towards paraphyrangeal space, or infratemporal fossa. Dislocating the maxillary third molar in infratemporal fossa is one of the worst nightmare as this area has complex anatomy consisting of vital neurovascular tissues and complex fascial spaces. The extent of displacement depends upon anatomical conditions as well as direction and amount of force applied. Complication arises from error in judgment, improper use of instruments, the application of extreme force or failure to obtain full visualization before acting. Various researchers have given their opinion regarding immediate or delayed removal of tooth pushed in infratemporal fossa but almost all agree that each case should be weighed independently for risk and reward before attempting. Here we present a case in which intraoral approach was taken to retrieve the displaced tooth thus preventing potentially dreadful complications.
\end{abstract}

Key words: exodontia complication, infratemporal fossa, tooth dislodgement. 


\section{Introduction}

Dislodgement of maxillary third molar into an adjacent infratemporal fossa is a rare complication of exodontias (1). Since this area consists of vital neurovascular tissues, pterygoid plexus of veins, branches of mandibular nerve, chorda tympani, maxillary artery and complex fascial planes, the situation arising hence may lead to dangerous complications like massive trans and post operative bleeding, chronic trismus, neurologic injury and paraphyrangeal space infection of serious nature (2). This case presents surgical removal of maxillary third molar dislodged in the fossa during its unsuccessful removal by a general dentist and that too under compromised circumstances hereby passing on a stern message across naive and overzealous young dentists that exodontias particularly pertaining to third molar should not be taken trivially and one should know limits of his competence, skill and environment in which one is working. Proceeding to retrive tooth without planning and knowledge of area can place both operator and patient in grave trouble.

\section{Case report}

A 35 year old underprivileged female, visited a petty charitable dental clinic for extraction of infected right maxillary third molar. The dental surgeon, after making exhaustive attempt to extract the tooth (18) for 2 hours, finally ended up in losing grip and visibility pushing it to an inaccessible site.

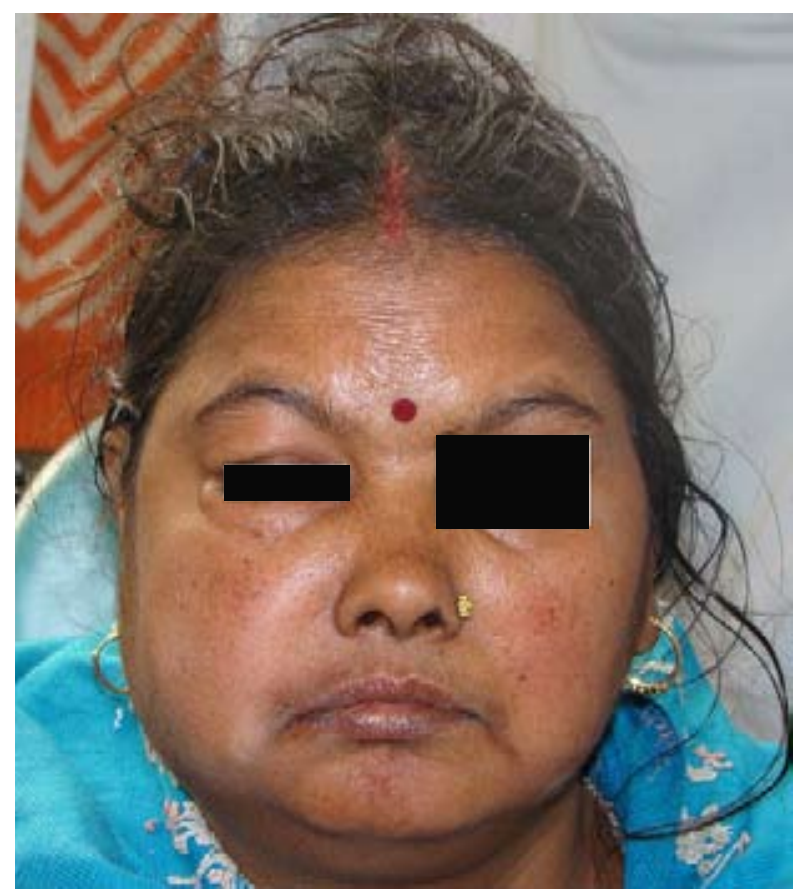

Fig.1. Patient in distress

The patient was completely exhausted, uncooperative and fearful(Fig.1). Surgical wound was arbitrarily teared tissue, Bichat's pad was ruptured, buccal commis- sure abraded, fat pad exposed due to violent, abrupt and forceful movements made during overzealous attempt to extract tooth. Moreover her capacity to open mouth was limited due to hematoma formation and yet she was repeatedly insisting on getting the tooth out.

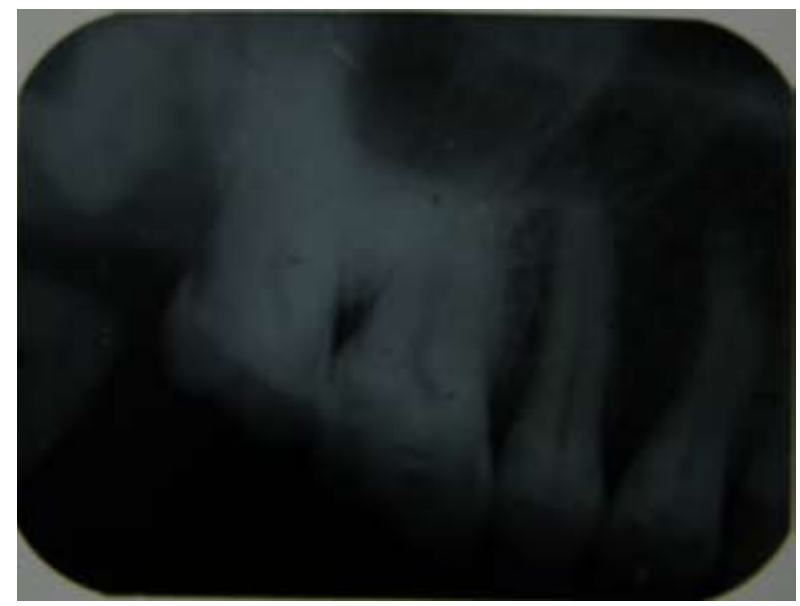

Fig.2. Pre operative radiograph

On assessing situation and having written consent we decided to go by intraoral approach under local anesthesia. Intra oral periapical radiograph were taken again at different angles to locate position of tooth (Fig.2). It was almost confirmed that tooth was pushed to infratemporal fossa posterior to maxillary tuberosity with its crown direction towards upper medial portion of coronoid apophysis of mandible. Emergency equipments were prepared. Access was obtained by linear vertical incision following the supero-anterior border of coronoid process of mandible. A palatal diagonal incision was placed in form of straight line extending from buccal vestibule in front of distal part of maxillary second molar to palatal aspect (up to $5 \mathrm{~mm}$ on palatal aspect) touching distobuccal line angle of maxillary second molar. After blunt divulsion with curved haemostatic forcep, it became possible to get tactile sense of tooth. The tooth was protected against posterior dislodgement using angled

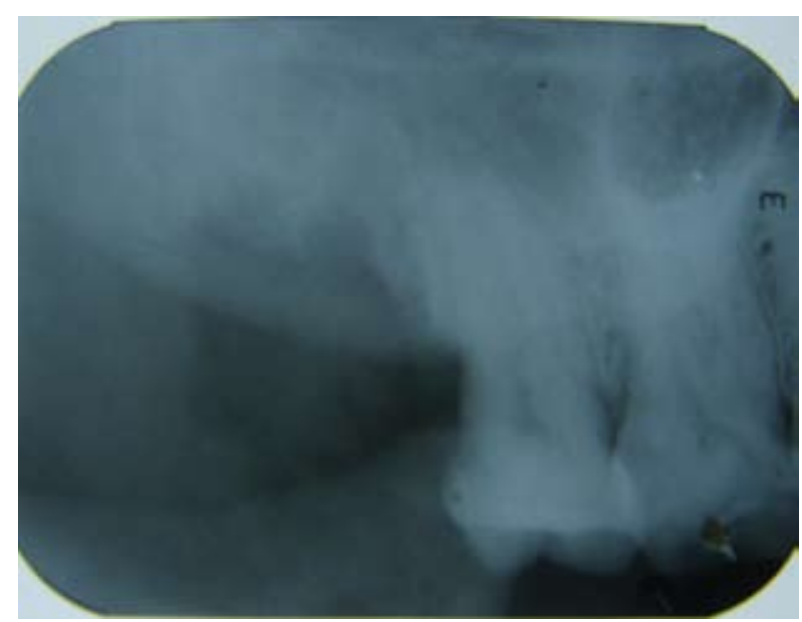

Fig.3. Post operative radiograph 
curette and was grasped with elle's forcep, after which surrounding tissue was freed by blunt dissection to take out tooth (Fig.3). Patient was discharged and returned to complete normalcy in 10 days.

\section{Discussion}

The major cause of displacement of third molar in infratemporal fossa are : poor surgical plan, inadequate flap, distorted or out of view radiographs, inappropriate use of surgical instruments, abrupt movement while instrumentation, distolingual angulation of tooth and lack of knowledge of regional topographic anatomy on part of surgeon $(2,3)$. All this may lead to injuries to teeth and adjacent structure, profuse bleeding, lateral and paraphyrangeal space infection, nerve injury, tuberosity fracture etc $(2,3)$.

In case the tooth is displaced in infratemporal fossa - it typically migrates in a posterosuperior direction, but the extent of the displacement depends upon the direction and amount of force. Maxillary third molars are usually displaced through the periosteum into the infratemporal fossa and located lateral to the lateral pterygoid plate and inferior to the lateral pterygoid muscle (2). In general practice setting, once it is established that the tooth has been displaced, it is sometimes still possible to manipulate maxillary third molar toward the socket with finger pressure applied high in the buccal sulcus. If it fails, an aspirator tip can also be tried to retrive tooth/ fragment.

Various researchers argue differently on whether the removal should be done immediately or should be delayed in case of displaced maxillary third molar. Ertas (4) preferred to perform surgery at the same time of tooth displacement as delay may lead to foreign body reaction, further dislocation and disturbed mental state of patient while others advocated to wait for few weeks as according to them movement of tooth is unlikely because of anatomy of area and fibrosis (5) but finally the decision should be guided by the precise location of the tooth, the signs and symptoms presented by the patient, the surgeon's knowledge and skill, and the patient's wish (6).

Once it has been decided to retrieve lost maxillary third molar from infratemporal fossa, then the selection of technique becomes important. There are multiple techniques that have been mentioned in literature. Winkler et al (1) advocated removal of tooth from infratemporal areas via transantral approach through careful dissection of posterior wall of maxillary sinus. In extraoral approach under general anesthesia Gillie's approach (7) can be made by the incision in the hairline: in this approach the displaced tooth is palpated and pushed inferiorly using a howarth periosteal elevator deep into temporal fascia. Same technique with a change of using an 18 gauze spinal needle with insitu instead of howarth ele- vator to push tooth inferiorly avoids the need for an incision in the temporal region has been mentioned by Orr (8). Sverzut et al (7) mentioned a case where tooth was not so deeply displaced into the infratemporal fossa and was retrieved by intraorally under local anaesthesia. In present case too intraoral approach with diagonal palatal flap design was used to provide unrestricted access to maxillary tuberosity region. This flap permitted placement of a suitable retractor, preventing displacement of maxillary third molar during its removal. It is rare to find tooth dislodged in infratemporal fossa and even rarer to have indications for its immediate removal, as in most cases tooth is left as such so that fibrosis develops which limits its movement during removal at a later date. All the indications for immediate surgical removal including pain, trismus, hematoma, infected tooth, patient insistence were there in present case. An old adage summarizes it all that the last thing a surgeon learns in his career is "when not to operate or when to stop operating" which holds true for any dental surgeon also. Thus we may here say that a dreadful accident with even worse sequelae could have happened which was prevented by timely and proficient intervention.

\section{References}

1. Winkler T, von Wowern N, Odont L, Bittmann S. Retrieval of an upper third molar from the infratemporal space. J Oral Surg. 1977; $35: 130-2$.

2. Dimitrakopoulos I, Papadaki M. Displacement of a maxillary third molar into the infratemporal fossa: case report. Quintessence Int. 2007;38:607-10

3. Patel M, Down K: Accidental displacement of impacted maxillarythird molars. Br Dent J 1994; 177 ( 2): 57-9.

4. Ertas U,Yaruz MS, Tozoglu S. Accidental third molar displacement into the lateral phyrangeal space. J Oral Maxillofac Surg 2002; 60:1217

5. Gulbrandsen SR, Jackson IT, Turlington EG. Recovery of a maxillarythird molar from the infratemporal space via a hemicoronal approach. J Oral Maxillofac Surg 1987; 45:279- 82.

6. Sverzut CE, Trivellato AE, Sverzut AT, de Matos FP, Kato RB. Removal of a maxillary third molar accidentally displaced into the infratemporal fossa via intraoral approach under local anesthesia: report of a case. J Oral Maxillofac Surg 2009;67:1316-20.

7. Dawson K, MacMillan A. Wiesenfeld D. Removal of maxillary third molar from infratemporal fossa by a temporal approach and the aid of image - intensifying cineradiography. J. Oral maxillofac surg 1993; 51(12):1395-7.

8. Orr DL 2nd: A technique for recovery of a third molar from the infratemporal fossa: Case report. J Oral Maxillofac Surg 1999; 57:1459-61 